\title{
A national fire behaviour knowledge base for enhanced information management and better decision making
}

\author{
$\underline{\text { Andrew Sullivan }^{\mathrm{a}}, \text { Jim Gould }^{\mathrm{a}} \text {, Miguel Cruz }}{ }^{\mathrm{a}}$, Chris Rucinski ${ }^{\mathrm{b}}$ and Mahesh Prakash ${ }^{\mathrm{b}}$ \\ ${ }^{a}$ CSIRO Ecosystem Sciences and CSIRO Digital Productivity and Services Flagship \\ ${ }^{b}$ CSIRO Computational Informatics and CSIRO Digital Productivity and Services Flagship \\ Email: Andrew.Sullivan@csiro.au
}

\begin{abstract}
Accurate prediction of bushfire behaviour is essential for effective fire management. Such knowledge allows for the timely determination of the potential threat and impacts of a fire and provides the basis for sound fire-management decision-making. Fire behaviour prediction combines quantitative and qualitative information sources that are based on scientific principles and personal experience describing the combustion and behaviour of fire in a range of weather, fuel and topographic conditions. 'Amicus', the National Fire Behaviour Knowledge Base, is a new software-based tool under development that endeavours to provide a unique framework in which each of these information sources is accessible and utilisable in a consistent and comprehensive manner for the sole purpose of operational prediction of the behaviour of bushfires by trained fire behaviour analysts.
\end{abstract}

The Amicus system comprises four primary components: fuel description, fuel moisture models, wind models and fire behaviour models and uses these to predict fire characteristics (e.g. rate of spread, flame height, fireline intensity, onset of crowning, spotting potential) for a broad range of burning conditions. This paper details the current development of the fire behaviour component of Amicus and its proposed integration with the Australian Bushfire Fuel Classification System being developed for use across all Australian jurisdictions. The fire behaviour component will integrate a suite of fire behaviour models covering the main Australian fuel types: eucalyptus forests, exotic pine plantations, grasslands and shrublands.

Further development of Amicus will integrate the fire weather, fuel dynamics, and suppression capability knowledge and science to help fire managers better predict bushfire behaviour and better plan prescribed burns.

Keywords: Bushfire, fire spread, fire prediction, fire models, software development, Workspace, workflow 


\section{INTRODUCTION}

Bushfires (wildland or forest fires as they are known in other parts of the world) are one of the world's most complex and dangerous natural phenomena, involving interactions of chemical, physical and biological processes across a broad range of temporal and spatial scales. Bushfires affect all populated continents. In recent years devastating bushfires with a heavy human toll occurred in Russia, the USA, Greece and Spain.

In Australia, more than 300 people have been killed by bushfires in the last 50 years. In 2001 bushfires were estimated to cause, on average, over $\$ 77 \mathrm{M}$ damage each year (Error! Reference source not found.). The Black Saturday fires in Victoria in 2009 burnt more than 400,000 ha, killed 173 people (Error! Reference source not found.) and caused over $\$ 1 \mathrm{~B}$ damage (Error! Reference source not found.) with a total estimated cost of \$4B (Error! Reference source not found.). The largest of these, the Kilmore East fire, burnt 100,000 ha in 12 hours (Error! Reference source not found.) and killed 121 people.

Predicting the behaviour of a bushfire is essential for the effective and timely management and control of fire in the landscape. Knowing how fast a bushfire will spread, where it will be at a given time, how resistant it will be to control, and what strategies would be effective in reducing the likelihood of recurrence are essential to fire fighter safety, community protection and safety, as well as planning and executing suppression. Assessment of fire behaviour potential is also essential for planning and conducting hazard reduction burns, for environmental or ecological purposes, and for creating landscapes with a low likelihood of large fire development. As such, fire behaviour knowledge provides critical information for formulating and enacting suppression and containment tactics and strategies but also situation awareness for all levels of fire management, from the frontline fire fighter who needs to identify local dangers, he sector commander who needs to ensure the safety of fire crews, to the incident controller who is responsible for the safety of all personnel on a fire ground and the community at risk..

In Australia, there are a number of empirical operational fire prediction systems (Error! Reference source not found., Error! Reference source not found.). These systems generally take the form of statistical regression models that relate key independent environmental variables (e.g. fuel, weather, topography) to a range of dependent variables such as rate of forward spread, flame height, spotting distance, etc). Each system is generally defined for a particular type of fuel (e.g. grassland, forest litter, forest crowns, heath) under a restricted range of burning conditions. The physical forms of these systems range from slide rules (Error! Reference source not found., Error! Reference source not found.) and nomograms and tables (Error! Reference source not found., Error! Reference source not found.). Often these are also coded up in the form of spreadsheets and computer programs.

Being predominantly statistical in origin, operational fire behaviour models are generally excellent at dealing with continuously varying parameters such as weather (wind speed, air temperature, etc.) and fuel moisture. However, vegetation is much more difficult to quantify to similar levels, primarily due to the natural biological variations in morphology and quantity, even within apparently uniform vegetation of the same type. The broad range of fuel and burning conditions in which wildfires can occur and the transitions between driving fuel layers within a particular vegetation type (the mechanisms for which are not well understood) present a significant challenge to many operational fire behaviour prediction systems.

For simplicity, vegetation fuels are categorised into a set number of discrete groups that allows qualitative and quantitative description. However, this approach presents a major challenge as the classified groups frequently do not match the breadth of $\mathrm{f}$ natural variation. Individuals making fire behaviour predictions commonly find fuels that do not seem to fit any standard fuel classification. They are then left to guess at how to classify their particular fuel, with the knowledge that even when classified, the predicted fire behaviour may not match observations due to differences between the local fuel and the most appropriate standard classification. Furthermore, the broad classifications necessary to make a system useable may incorporate a significant amount of variation within a fuel classification that results in predictions that do not match observations. In addition to this, the new trend to modified vegetation complexes through vegetation management introduces a new suite of fuel conditions not accounted in the currently used fire behaviour models.

Existing fire spread simulation tools such as SiroFire (Error! Reference source not found.), FARSITE (Error! Reference source not found.), Phoenix (Error! Reference source not found.), PROMETHEUS (Error! Reference source not found.), and FSPro (Error! Reference source not found.), link geographic information system databases for topography, vegetation and other landscape features with meteorology information and fire behaviour models in order to simulate fire perimeter propagation across the landscape. However, these for the most part utilise available operational fire spread prediction models and therefore suffer the same fuel-class related problem as less advanced systems. 
The proposed solution to this seemingly intractable problem is not the development of yet another model for a particular type and arrangement of fuel. We propose the development of a fire behaviour knowledge base that supersedes existing physical forms of fire behaviour prediction systems and allows fire practitioners to view historical fire behaviour observations directly in parallel with model predictions (and the possible variation in fire behaviour), with a richness and depth of information difficult to achieve using traditional modelling methodologies.

\section{AMICUS, A NATIONAL FIRE BEHAVIOUR KNOWLEDGE BASE}

This paper presents a proposal for a National Fire Behaviour Knowledge Base aimed at addressing the needs of fire managers in regards to improving access to critical fire behaviour information in a timely, effective and efficient manner. This includes information on fuel (type, condition, state, hazard), expected fire weather, and the prediction of site specific fire behaviour. The purpose of the system is to integrate all (available and) peer-reviewed fire behaviour knowledge into a single user-friendly interface that enhances the information available to the fire manager and enables linkages to other critical sources of information such as current and forecast weather.

This system, called 'Amicus' (derived from the legal Latin term amicus curiae, 'independent advisor') will consist of a suite of tools that can be used by managers to deal with fire management issues over a range of spatial and temporal scales as well as levels of decision making complexity. Such a system will enhance fuel management programs, lead to more effective and safer firefighting, improve protection of rural communities, infrastructure and other assets and reduce detrimental effects to natural resources.

The Amicus system is envisioned as a searchable, extendable database that allows users to:

- describe their current fuel complex and have the computer search through a database of existing fuel and fire behaviour observations to find similar conditions;

- review photos of similar fuels and select those that best match their current area of concern;

- review available general and detailed data concerning the weather, topography and resultant fire behaviour for each of the selected fuel complexes;

- review images and video taken before, during and after fires burning in similar conditions;

- plot the data against existing mathematical model results to see how existing models predict parameters for selected fuel complex matches;

- access publications linked to the displayed observations for in-depth information and analysis; and

- insert data and documentation (photos, video) of their own fires to build the knowledge base.

The heart of Amicus is comprised of two modules (Figure 1): the fire behaviour models module (currently being developed) and a fire behaviour knowledge base module (future work). The fire behaviour module is the engine of the system, providing fire behaviour predictions aimed at answering a wide range of fire management questions (Error! Reference source not found.). It will initially be populated with the state-of the art fire behaviour models for prescribed burning and wildfire propagation. These models will be augmented with observational data sets derived from experimental fires as well as reliably documented wildfire events. The main fire behaviour quantities that will be determined by the fire behaviour module are:

- $\quad$ sustainability of fire spread,

- initial fire development potential (area and perimeter assuming point ignition),

- rate of forward fire spread and intensity of surface fire,

- flame dimensions (height, depth, angle) and residence time,

- spotting potential,

- onset of crowning and crown fire behaviour, and

- fine and coarse woody fuel consumption.

Ensemble calculations of fire behaviour will be carried out to incorporate the inherent spatial and temporal variability in weather and fuel conditions, providing users with measures of uncertainty associated with specific fire behaviour forecasts.

Notwithstanding the comprehensiveness of the core fire behaviour dataset (based on six decades of fieldbased fire experimentation and wildfire analysis), the system will still not cover all possible burning conditions (fuels, weather and topographic combinations) that may be encountered by fire managers. Thus, predictions for conditions which do not match any observations in the historical record within the knowledge base would have greater uncertainty than otherwise. 
A unique aspect of the system architecture planned for Amicus is the ability for the knowledge base to be user extendable. By allowing users to append verified observations of their own fuel, burning conditions and associated fire behaviour means Amicus will eventually become a comprehensive crowd-sourced database that is applicable to the broad range of combinations of fire conditions. The observations that users make and the knowledge they gain from making those observations will be made available (after verification) to the larger fire management community to enhance the quality of decisions making. That is, a fire manager can immediately access information about previous fire behaviour observations made in current similar fuel and burning conditions and be able to make better fire behaviour predictions and thus decisions.

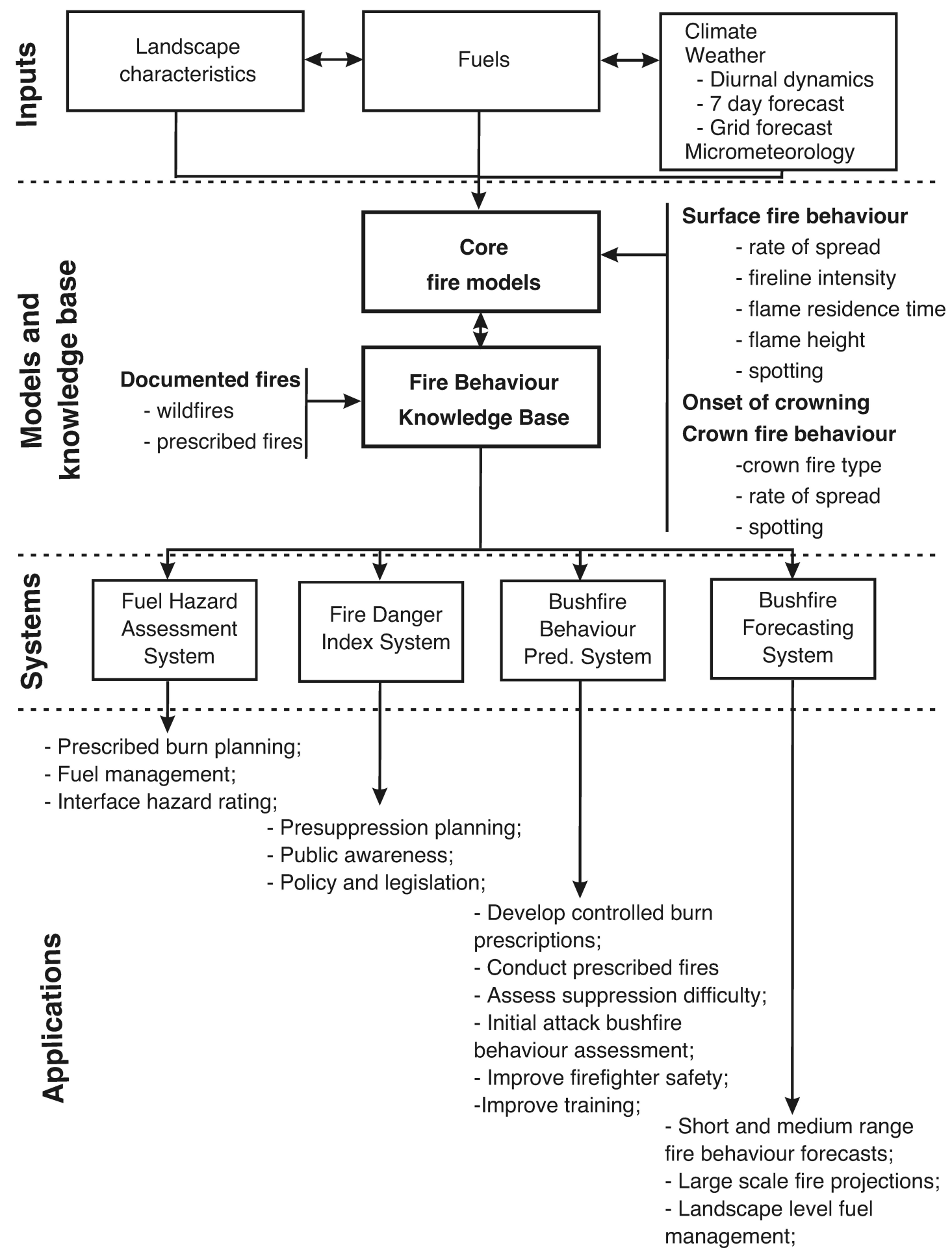

Figure 1. Flow diagram of the proposed National Fire Behaviour Knowledge Base 'Amicus' structure, illustrating the link between fire drivers, the knowledge base (models and data) and output systems and potential applications (Source: Cruz and Gould, 2009). 


\section{SOFTWARE DEVELOPMENT}

Amicus is being built using the Workspace workflow environment developed by the CSIRO Computational Informatics Computational Modelling Group. Workspace was chosen as the development platform because it is a cross-platform scientific workflow engine available on Windows, Linux and OSX. Workspace is written predominantly in $\mathrm{C}++$ which is inherently beneficial in terms of scalability and performance.

A Workspace workflow is made up of a series of "operations" (Figure 2 shows one such purpose-built operation). Each operation has a series of input and output ports on its left and right side respectively. An operation can perform a calculation based on its inputs and then output some data. A user can connect a number of operations together to perform a complex series of calculations on streams of data, thus forming a workflow.

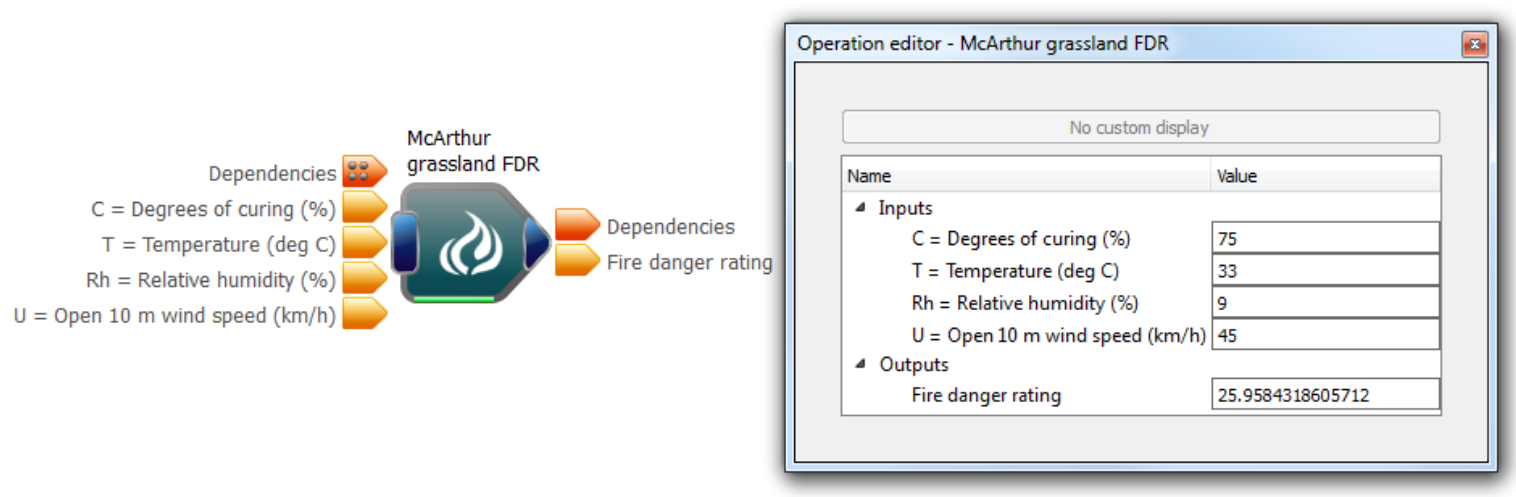

Figure 2. An example of a Workspace operation that calculates fire danger rating for grasslands. Input and output values of the operation are shown in the operation editor window.

Workspace users may construct, modify and execute workflows using an intuitive graphical editor (Figure 3). This editor allows users to inspect and modify any input or output on the workflow using custom built display widgets allowing interaction with workflows as they're executing.

Users can access a large suite of built-in operations and data types. New operations, data types and display widgets can be added easily. Workspace assists users in this task by providing extensive tutorials and wizards.

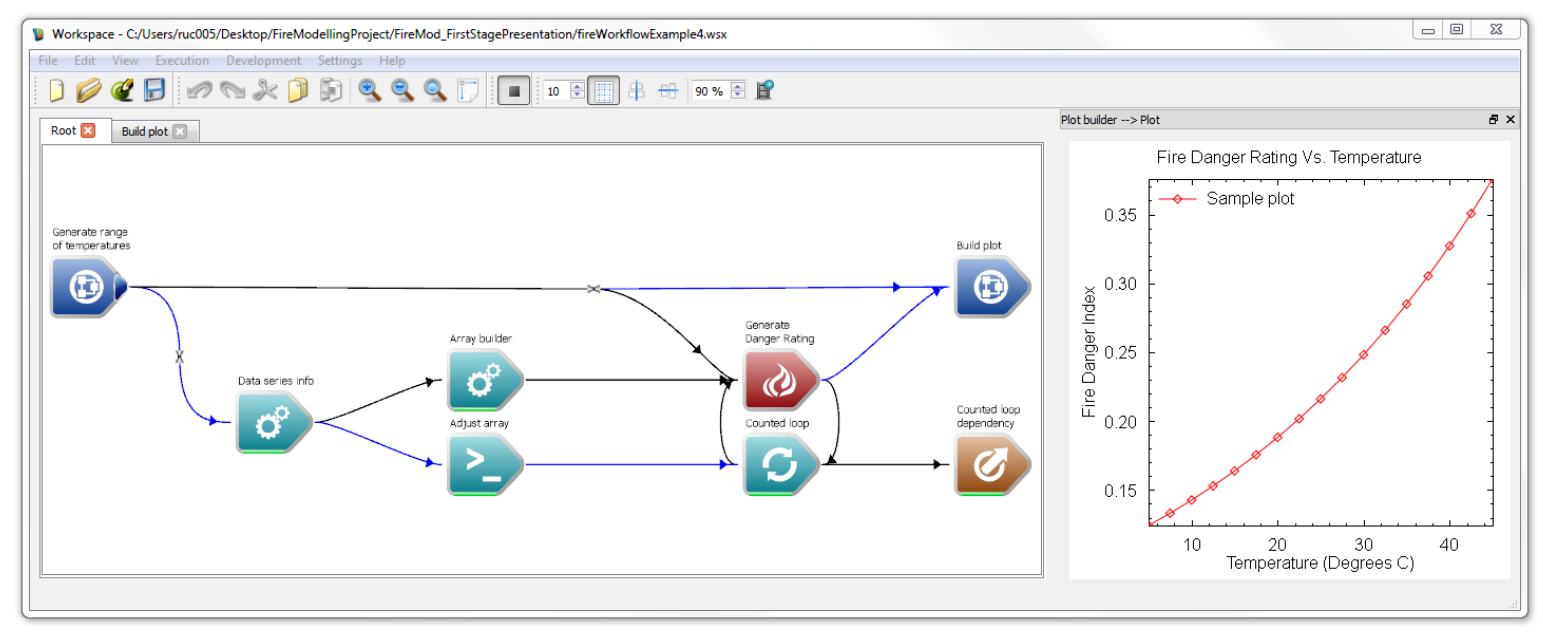

Figure 3. A workflow that plots temperatures against fire danger indices using newly developed Workspace fire model operations.

Workspace also supports the creation of complete custom Graphic User Interfaces (GUI) to simplify end-user interaction with workflows (Figure 4). As Workspace is built upon the Qt software development framework ${ }^{1}$, it includes a large library of GUI widgets out of the box. Developers can also define new widgets or derive new widgets from existing ones.

\footnotetext{
${ }^{1}$ www.qt-project.org
} 


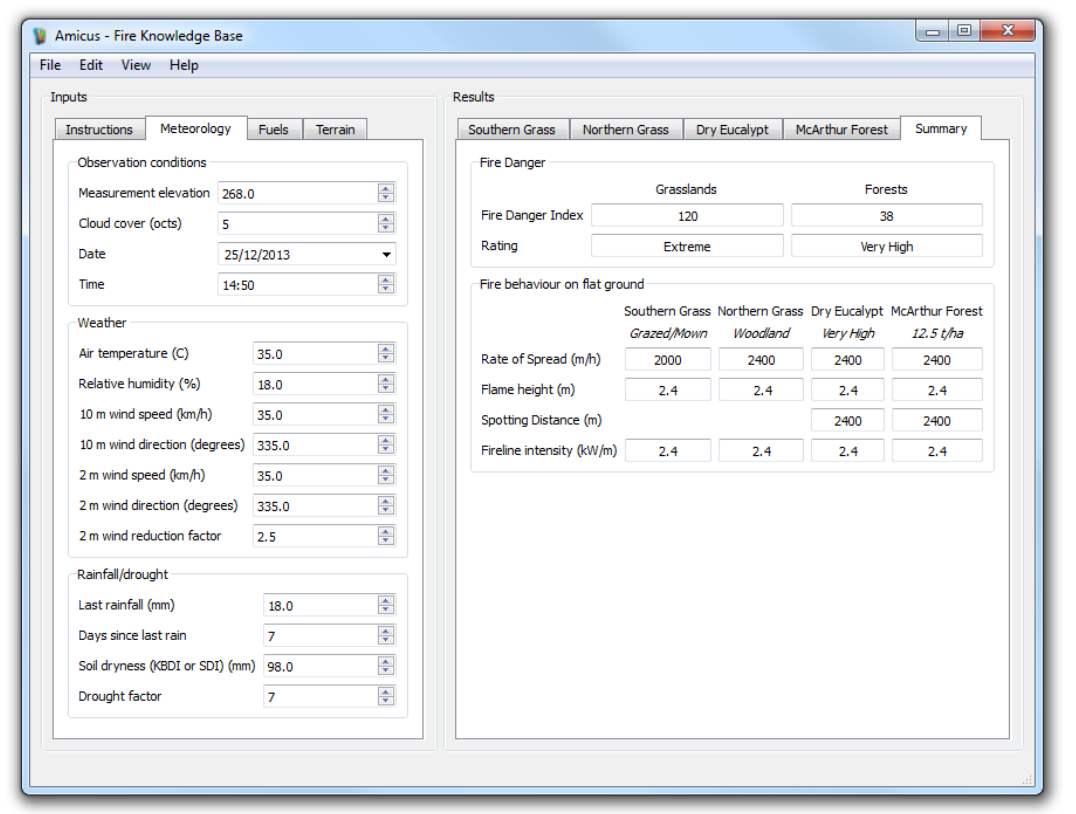

Figure 4. A preview of the Amicus interface currently under development. This front-end provides a simple interface for end-users to control a workflow.

\section{AGENCY LINKAGES AND USE}

Amicus will be a powerful tool for fire behaviour analysis and prediction. However without a cohort of individuals well-trained to predict fire behaviour, the tool will enjoy little effective use. Trained and experienced Fire Behaviour Analysts (FBANs) are a critical part of any fire intelligence team reporting into an Incident Management Team. Amicus is first and foremost an operational tool for FBANs. As such it is expected that a multi-agency cadre of FBAN's and other users and researchers would oversee database management, ensure data quality and recommend improvements to the software.

A second benefit of Amicus is a centralised repository of national fire behaviour data. These data will then be easily accessible to scientists as well as to agency staff for a variety of research and planning purposes. This data set, larger than any existing single dataset, could provide powerful insights into the nature of fire in Australia and how best to manage it.

Finally, because Amicus has the capacity to include visual documentation (still and video photography) of pre-, during and post-burn observations, there will be application to prescribed burning planning and preparation. Users can identify a fuel condition of interest, view the range of post-burn results, select the appropriate post-burn consequences that they would like to obtain and then review the necessary weather and fuel conditions required to achieve them.

\section{CONCLUSIONS AND FUTURE WORK}

Development of Amicus is at an early stage. However its simple but encompassing concept is garnering interest in many locations. Because it is not dependant on any single fire behaviour prediction system, it is seen as a potential complement to existing fire behaviour modelling tools and as an essential element for front line fire behaviour prediction and operational decision making.

While the fuel conditions in Australia vary quite markedly across the continent, there are some that have similar attributes or that burn in a similar manner. The merging of the fuel data from the developing National Fuel Classification System (Error! Reference source not found., Error! Reference source not found.) can only improve our overall understanding and prediction of fire nationally. Amicus and the National Fire Behaviour Knowledge Base framework provide the potential to develop a truly national tool integrating the large pool of fire behaviour data that is available across the country. The resulting knowledge base will be unparalleled in richness and depth and will significantly improve the quality of both fire behaviour prediction and decision making. 


\section{ACKNOWLEDGEMENTS}

Thanks to Ryan Fraser and the Disaster Management stream within the CSIRO Digital Productivity and Services Flagship Government and Commercial Services Theme for funding this endeavour. Thanks also to Drs Peter Ellis and Matt Plucinski and two anonymous referees for providing constructive comments on the manuscript.

\section{REFERENCES}

BTE (2001). Economic costs of natural disasters in Australia. Economics Report 103, Bureau of Transport, Canberra, ACT.

Coleman, J. R. and Sullivan, A. L. (1996). A real-time computer application for the prediction of fire spread across the Australian landscape. Simulation, 67(4):230-240.

Cruz, M. G. and Gould, J. (2009). National fire behaviour prediction system. In Proceedings of the Biennial Conference of the Institute of Foresters of Australia, 6-10 October 2009, Caloundra, Qld, p. 285-291.

Cruz, M. G., Sullivan, A. L., Gould, J. S., Sims, N. C., Bannister, A. J., Hollis, J. J., and Hurley, R. (2012). Anatomy of a catastrophic wildfire: The Black Saturday Kilmore East fire in Victoria, Australia. Forest Ecology and Management, 284:269-285.

Finney, M. A. (1998). FARSITE: Fire area simulator-model development and evaluation. Research Paper RMRS-RP-4, USDA Forest Service, Rocky Mountain Research Station.

Finney, M. A., Grenfell, A. C., McHugh, C. W., Seli, R. C., Trethewey, D., Stratton, R. D., and Brittain, S. (2011). A method for ensemble wildland fire simulation. Environmental Modeling and Assessement, 16(2):153-167.

Gould, J. and Cruz, M. (2012). Australian fuel classification: Stage II. Technical report, CSIRO Ecosystem Sciences and CSIRO Climate Adaption Flagship, Canberra, Australia.

Gould, J. S., McCaw, W. L., Cheney, N. P., Ellis, P. F., Knight, I. K., and Sullivan, A. L. (2007a). Project Vesta-Fire in Dry Eucalypt Forest: fuel structure, dynamics and fire behaviour. Ensis-CSIRO, Canberra ACT, and Department of Environment and Conservation, Perth WA, Canberra, ACT.

Gould, J. S., McCaw, W. L., Cheney, N. P., Ellis, P. F., and Matthews, S. (2007b). Field Guide: Fire in Dry Eucalypt Forest. Ensis-CSIRO, Canberra, and Department of Environment and Conservation, Perth WA.

Hollis, J., Gould, J., Cruz, M., and Doherty, M. (2011). Scope and framework for an Australian fuel classification. Report for Australasian Fire and Emergency Services Authorities Council. Client Report No. EP113652, CSIRO Ecosystem Sciences and CSIRO Climate Adaptation Flagship, Canberra.

Insurance Council of Australia (2010). Insurance Council of Australia: Year in Review 2009. , Insurance Council of Australia, Sydney.

McArthur, A. G. (1966). Weather and grassland fire behaviour. Forestry and Timber Bureau Leaflet 100, Commonwealth Department of National Development, Canberra.

McArthur, A. G. (1967). Fire behaviour in eucalypt forests. Forestry and Timber Bureau Leaflet 107, Commonwealth Department of National Development, Canberra.

Sullivan, A. L. (2009a). Improving operational models of fire behaviour. In Anderssen, R. S., Braddock, R. D., and Newham, L. T. H., editors, 18th World IMACS Congress and MODSIM09 International Congress on Modelling and Simulation, 13-17 July 2009, Cairns, Australia, pages 282-288.

Sullivan, A. L. (2009b). Wildland surface fire spread modelling, 1990-2007. 2: Empirical and quasiempirical models. International Journal of Wildland Fire, 18(4):369-386.

Teague, B., McLeod, R., and Pascoe, S. (2010). 2009 Victorian Bushfires Royal Commission. Final report, State of Victoria, Melbourne, Victoria.

Tolhurst, K., Shields, B., and Chong, D. (2008). Phoenix: development and application of a bushfire risk management tool. The Australian Journal of Emergency Managment, 23(4):47-55.

Tymstra, C., Bryce, R. W., Wotton, B. M., Taylor, S. W., and Armitage, O. B. (2010). Development and Structure of Prometheus: the Canadian Wildland Fire Growth Simulation Model. Information Report NORX-417, Canadian Forest Service Northern Forestry Centre, Edmonton, Alberta. 